\title{
The efficacy of esmolol and nitroglycerine in creating dry operative field by producing controlled hypotension in spinal surgeries.
}

\author{
Himaunshu Dongre ${ }^{1}$ Vijay Sharma ${ }^{2}$, Benhur Premendran $^{3}$, \\ Aditi Dongre ${ }^{4}$, Sucheta Tidke 5 \\ ${ }^{1} M D$, Assistant professor, MGIMS-Sevagram-442102 \\ ${ }^{2} D A, M D, D N B$, Assistant professor, MGIMS-Sevagram-442102 \\ ${ }^{3} M D$, Associate professor, MGIMS-Sevagram-442102 \\ ${ }^{4}$ MD, Assistant professor, MGIMS-Sevagram-442102 \\ ${ }^{5}$ MD, Professor ,MGIMS-Sevagram-442102
}

\begin{abstract}
-
Introduction: Laminectomy and Spine Surgeries are associated with increased blood loss due to bleeding from the extensive epidural venous plexuses. Controlled hypotension is a time tested technique utilized for reducing blood loss and creating a blood less operative field. Esmolol and Nitroglycerine(NTG) are reportedly used in various surgeries for this purpose. As dry operative field is a fundamental component of spine surgeries this study intended to compare the dry operative field created by esmolol with NTG.

Material and Methods: This single blinded randomized controlled trial was carried out on 50 adult patients undergoing spine surgeries and divided into two groups of 25 each. Group-E received Esmolol infusion while the Group-N received NTG infusion.Dosages were titrated to achieve controlled hypotension and optimum bloodless operative field.

Results: Systoloic, Diastolic and Mean arterial pressures were comparable in both the groups.Pulse rates in group-E were significantly lower $(P<0.05)$ as compared to that in group-N.Mean scores for quality of surgical field were comparable in both the groups however group $E$ required lower blood pressures to achieve it compared to group- $N$. Esmolol infusion required significantly higher cost than NTG for the above trial.

Conclusion: Both Esmolol and NTG can be used as a sole agent to create dry operative field in spine surgeries by way of controlled hypotension with comparable efficacy however NTG is more economical than esmolol for this purpose. Also dry operative field with NTG can be achieved at higher mean blood pressure values compared with use of esmolol.
\end{abstract}

\section{INTRODUCTION}

In orthopaedic procedures more blood is lost from raw bone and muscle surfaces than from identifiable blood vessels.A radio isotope study of blood lost in major orthopaedic procedures showed that estimates of blood losses were, on average, $50 \%$ of the true measured loss ${ }^{[1]}$ Laminectomy and spinal fusion are associated with increased blood loss due to bleeding from the extensive epidural venous plexuses and also poses a possibility of nerve injury at the root level if not visualized properly. Nerve roots are at jeopardy during cordotomy and laminectomy and decrease in haemorrhage adds to safety of surgery in this area. ${ }^{(2)}$.Reduced bleeding in the operative field not only facilitates surgery but also might improve surgical results.

Controlled hypotension is a time tested technique utilized for reducing blood loss and creating a blood less operative field. Moderate hypotensive anaesthesia was found to significantly decrease the average blood loss by nearly $40 \%$, reduced the need for transfusion by nearly $45 \%$ and shortened the average operating time by nearly $10 \%{ }^{[2]}$ Esmolol has been shown to create a better dry operative field than sodium nitroprusside in surgeries like tympanoplasy and various orthognathic surgeries. Nitroglycerine(NTG) has been used as an agent for controlled hypotension in orthopaedic procedures like hip replacement surgeries. As dry operative field is a fundamental component of spinal surgeries we intended to compare the dry operative field created by esmolol with NTG in spinal surgeries. 
The efficacy of esmolol and nitroglycerine in creating dry operative field by producing.....

\section{MATERIALS AND METHODS}

Setting :The present single blinded randomized study was carried out in the department of Anaesthesiology, MGIMS, Sevagram. The approval for the study was obtained from the ethical committee of MGIMS, Sevagram. Informed written consent was taken from patients who participated in this study.

Study Design : The study comprised of 50 patients of ASA grades I and II undergoing spine surgeries. They were randomly allotted to group $\mathrm{N}$ and group $\mathrm{E}$ for receiving nitroglycerine or esmolol for producing controlled hypotension.

Study Procedure : All patients were pre loaded with Ringer's lactate $7 \mathrm{ml} / \mathrm{kg}$. The pre anaesthetic medication was similar in all patients, consisting of inj glycopyrrolate $0.2 \mathrm{mg}$, inj midazolam $1 \mathrm{mg}$ and inj fentanyl $100 \mu \mathrm{gm}$. All patients were induced with inj propofol $1.5 \mathrm{mg} / \mathrm{kg}$ iv and inj succinylcholine $1.5 \mathrm{mg} / \mathrm{kg}$. The patients were maintained on 50:50 nitrous in oxygen, isoflurane and vecuronium and end tidal $\mathrm{CO}_{2}$ $\left(\mathrm{ETCO}_{2}\right)$ was maintained at or near $30 \mathrm{~mm} \mathrm{Hg}$. The induced hypotensive agent either NTG or esmolol was started and the desired level of hypotension (MAP 60-65 mm Hg) was achieved by the time cleaning and draping was done. Once the desired level of hypotension is achieved the skin was infiltrated with adrenaline 1:200000 concentration and then the incision was given. Throughout the procedure the concentration of isoflurane was kept constant and the hypotension was maintained by altering the infusion of either nitroglycerine or Esmolol. Inj NTG was started at the rate of $1 \mu \mathrm{gm} / \mathrm{kg} / \mathrm{min}$ and adjusted according to the requirement to reach satisfactory bloodless field. Inj Esmolol was given in the loading dose of $500 \mu \mathrm{gm} / \mathrm{kg} / \mathrm{min}$ for $90 \mathrm{sec}$ and then maintenance dose of $100-300 \mu \mathrm{gm} / \mathrm{kg} / \mathrm{min}$ for rest of the time and the dose titrated according to the desired hypotension required \& bloodless feild.

The operative field was judged by the same operating surgeon who was blinded to the induced hypotensive agent used using a scale as follows:

$0=$ No bleeding

$1=$ Slight bleeding no suctioning required

$2=$ Slight bleeding - occasional suctioning required, surgical field not threatened

$3=$ Moderate bleeding - frequent suctioning required

$4=$ Severe bleeding

The heart rate, invasive blood pressure, respiratory rate, ECG changes, $\mathrm{ETCO}_{2}$ and $\mathrm{SpO}_{2}$ were continuously monitored and recorded at $10 \mathrm{~min}$ interval. The operative field grading was recorded every 10 min.Results were noted and analysed by using software STATA 10.

\section{Observations \& results:}

Table1: table showing the mean pulse rates both pre operative and intra operative in both groups

\begin{tabular}{|l|l|l|l|}
\hline TIME & GROUP E & GROUP N & P VALUE \\
\hline PRE OPERATIVE & $75.84 \pm 4.65$ & $74.52 \pm 3.60$ & $>0.05$ \\
\hline 5 MINUTES & $77.84 \pm 4.62$ & $77.52 \pm 3.69$ & $>0.05$ \\
\hline 10 MINUTES & $72.92 \pm 4.41$ & $83.44 \pm 4.74$ & $<\mathbf{0 . 0 5}$ \\
\hline 20 MINUTES & $69.32 \pm 4.76$ & $85.76 \pm 3.17$ & $<\mathbf{0 . 0 5}$ \\
\hline 30 MINUTES & $67.84 \pm 5.06$ & $86.40 \pm 3.16$ & $<\mathbf{0 . 0 5}$ \\
\hline 40 MINUTES & $66.68 \pm 4.06$ & $86.88 \pm 2.38$ & $<\mathbf{0 . 0 5}$ \\
\hline 50 MINUTES & $64.88 \pm 4.28$ & $88.00 \pm 2.51$ & $<\mathbf{0 . 0 5}$ \\
\hline 60 MINUTES & $63.76 \pm 2.78$ & $89.12 \pm 3.16$ & $<\mathbf{0 . 0 5}$ \\
\hline 70 MINUTES & $63.68 \pm 2.74$ & $91.12 \pm 4.62$ & $<\mathbf{0 . 0 5}$ \\
\hline 80 MINUTES & $62.96 \pm 4.62$ & $91.04 \pm 5.00$ & $<\mathbf{0 . 0 5}$ \\
\hline 90 MINUTES & $62.40 \pm 3.95$ & $90.80 \pm 5.09$ & $<\mathbf{0 . 0 5}$ \\
\hline 100 MINUTES & $62.32 \pm 3.63$ & $88.40 \pm 3.31$ & $<\mathbf{0 . 0 5}$ \\
\hline 110 MINUTES & $63.57 \pm 3.54$ & $87.39 \pm 4.65$ & $<\mathbf{0 . 0 5}$ \\
\hline 120 MINUTES & $66.81 \pm 4.46$ & $83.57 \pm 3.00$ & $<\mathbf{0 . 0 5}$ \\
\hline 130 MINUTES & $68.75 \pm 4.07$ & $81.70 \pm 4.27$ & $<\mathbf{0 . 0 5}$ \\
\hline 140 MINUTES & $70.10 \pm 2.51$ & $83.00 \pm 4.24$ & $<\mathbf{0 . 0 5}$ \\
\hline
\end{tabular}

Table 2: table showing the pre operative and intra operative mean arterial pressure in both the groups 
The efficacy of esmolol and nitroglycerine in creating dry operative field by producing.....

\begin{tabular}{|l|l|l|l|}
\hline TIME & GROUP E & GROUP N & P VALUE \\
\hline PRE OPERATIVE & $88.48 \pm 4.28$ & $87.76 \pm 4.62$ & $\mathrm{P}>0.05$ \\
\hline 5 MINUTES & $69.96 \pm 2.24$ & $67.28 \pm 1.33$ & $\mathbf{P}<\mathbf{0 . 0 5}$ \\
\hline 10 MINUTES & $67.08 \pm 1.41$ & $66.12 \pm 1.50$ & $\mathbf{P}<\mathbf{0 . 0 5}$ \\
\hline 20 MINUTES & $66.44 \pm 2.02$ & $65.12 \pm 1.53$ & $\mathbf{P}<\mathbf{0 . 0 5}$ \\
\hline 30 MINUTES & $65.76 \pm 2.18$ & $65.16 \pm 1.54$ & $\mathrm{P}>0.05$ \\
\hline 40 MINUTES & $65.52 \pm 2.25$ & $64.92 \pm 1.07$ & $\mathrm{P}>0.05$ \\
\hline 50 MINUTES & $65.44 \pm 1.95$ & $65.12 \pm 1.42$ & $\mathrm{P}>0.05$ \\
\hline 60 MINUTES & $64.84 \pm 1.65$ & $64.76 \pm 1.23$ & $\mathrm{P}>0.05$ \\
\hline 70 MINUTES & $65.00 \pm 1.47$ & $66.08 \pm 1.70$ & $\mathbf{P}<\mathbf{0 . 0 5}$ \\
\hline 80 MINUTES & $65.28 \pm 1.88$ & $66.20 \pm 2.29$ & $\mathrm{P}>0.05$ \\
\hline 90 MINUTES & $65.79 \pm 1.79$ & $67.36 \pm 3.08$ & $\mathbf{P}<\mathbf{0 . 0 5}$ \\
\hline 100 MINUTES & $67.32 \pm 3.70$ & $69.54 \pm 3.96$ & $\mathbf{P}<\mathbf{0 . 0 5}$ \\
\hline 110 MINUTES & $70.48 \pm 6.09$ & $71.33 \pm 5.48$ & $\mathrm{P}>0.05$ \\
\hline 120 MINUTES & $73.45 \pm 7.06$ & $73.11 \pm 4.53$ & $\mathrm{P}>0.05$ \\
\hline 130 MINUTES & $75.64 \pm 7.11$ & $76.20 \pm 8.10$ & $\mathrm{P}>0.05$ \\
\hline 140 MINUTES & $76.66 \pm 6.02$ & $73.50 \pm 5.70$ & $\mathrm{P}>0.05$ \\
\hline 150 MINUTES & $80.33 \pm 1.52$ & $76.00 \pm 0.00$ & $\mathrm{P}>0.05$ \\
\hline
\end{tabular}

Table 3: table showing the dry operative field at various time intervals during spine surgery.

\begin{tabular}{|l|l|l|l|l|l|l|l|l|l|l|}
\hline & \multicolumn{7}{l}{ GIME } & \multicolumn{7}{l|}{ GROUP N } \\
\hline & 0 & 1 & 2 & 3 & 4 & 0 & 1 & 2 & 3 & 4 \\
\hline & & & & & & & & & & \\
\hline & 0 & 0 & 22 & 3 & 0 & 0 & 0 & 22 & 3 & 0 \\
\hline $\mathbf{2 0}$ MIN & 0 & 0 & 20 & 4 & 1 & 0 & 0 & 16 & 8 & 1 \\
\hline $\mathbf{3 0}$ MIN & 0 & 5 & 16 & 4 & 0 & 0 & 4 & 15 & 6 & 0 \\
\hline $\mathbf{4 0}$ MIN & 0 & 8 & 15 & 2 & 0 & 1 & 9 & 14 & 1 & 0 \\
\hline $\mathbf{5 0}$ MIN & 4 & 6 & 14 & 1 & 0 & 2 & 13 & 10 & 0 & 0 \\
\hline $\mathbf{6 0}$ MIN & 4 & 5 & 15 & 1 & 0 & 2 & 14 & 9 & 0 & 0 \\
\hline $\mathbf{7 0}$ MIN & 4 & 5 & 16 & 0 & 0 & 2 & 15 & 8 & 0 & 0 \\
\hline $\mathbf{8 0}$ MIN & 1 & 8 & 9 & 0 & 0 & 3 & 8 & 9 & 0 & 0 \\
\hline $\mathbf{9 0}$ MIN & 1 & 6 & 3 & 0 & 0 & 0 & 6 & 7 & 0 & 0 \\
\hline $\mathbf{1 0 0}$ MIN & 0 & 1 & 0 & 0 & 0 & 1 & 0 & 1 & 0 & 0 \\
\hline $\mathbf{1 1 0}$ MIN & & & & & & & & \\
\hline
\end{tabular}


GRAPH-1

COMPARISON OF PULSE RATE IN TWO GROUPS

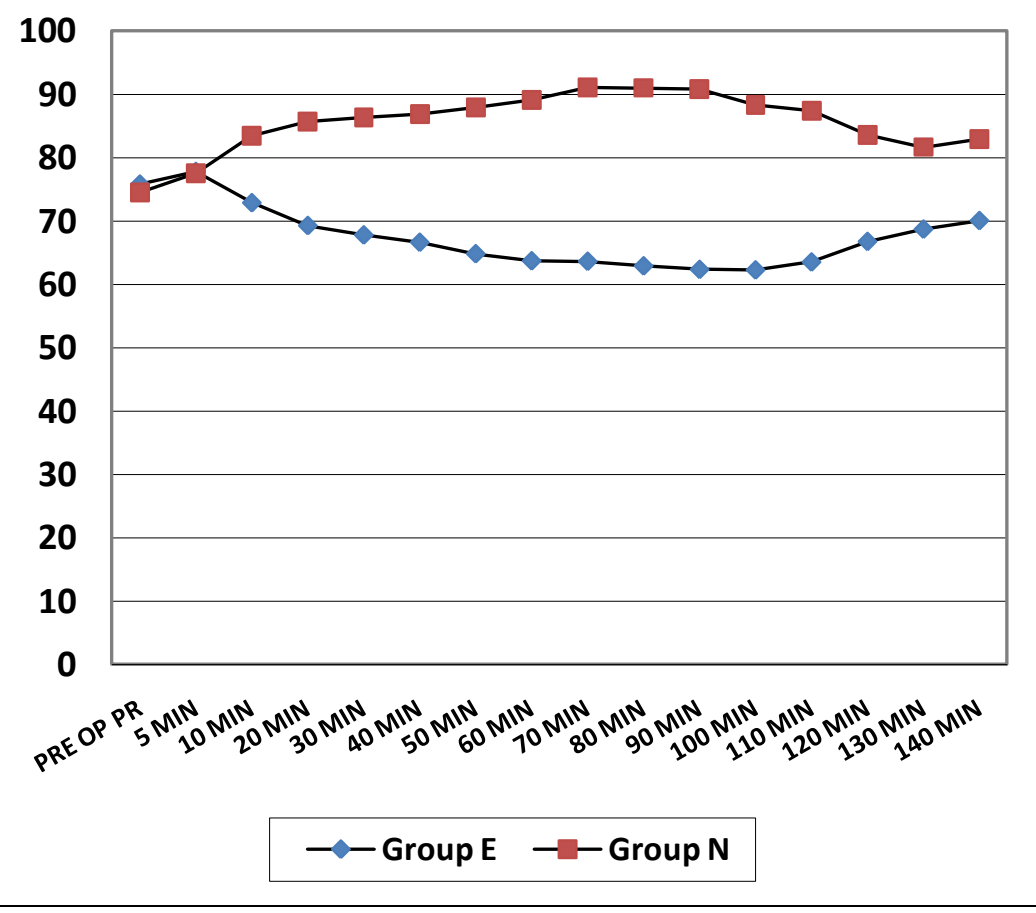

GRAPH-2

COMPARISON OF MEAN ARTERIAL PRESSURE

BETWEEN TWO GROUPS

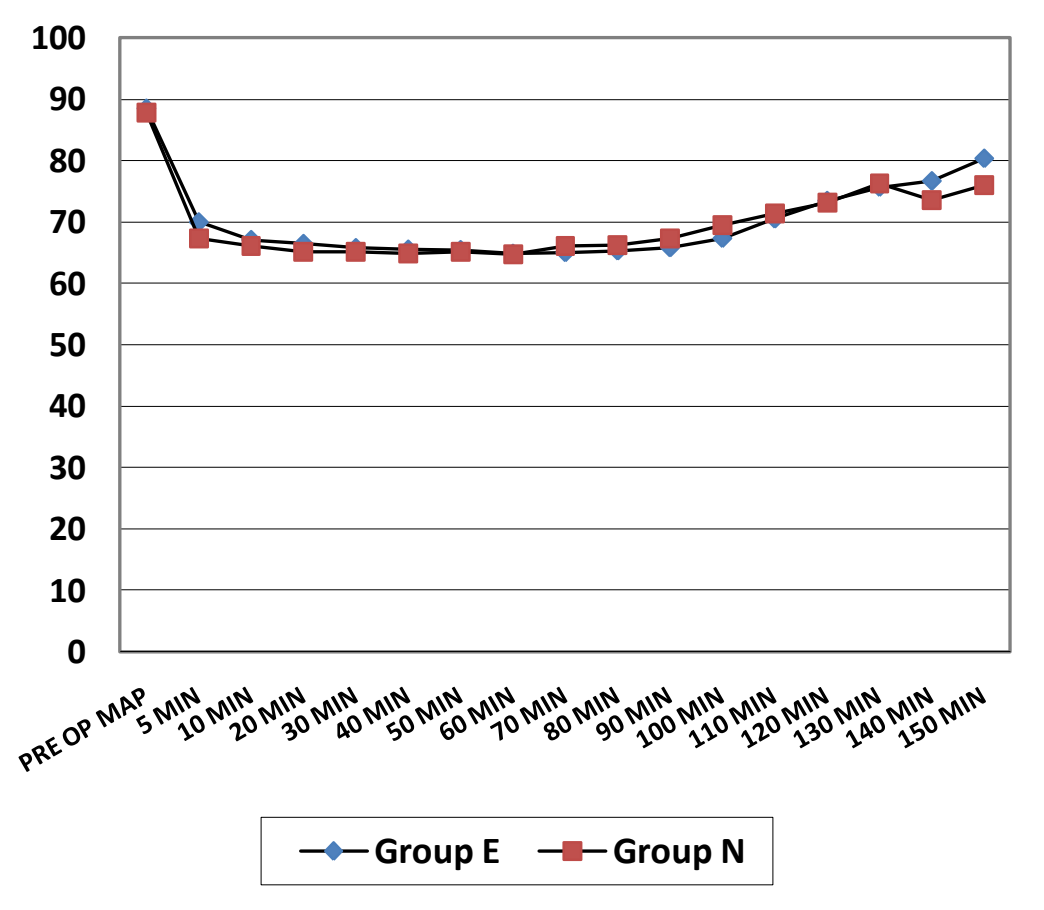




\section{GRAPH-3}

SCORES AT VARIOUS TIME INTERVALS TO JUDGE

THE DRY OPERAIVE FIELD IN CASE OF GROUP E

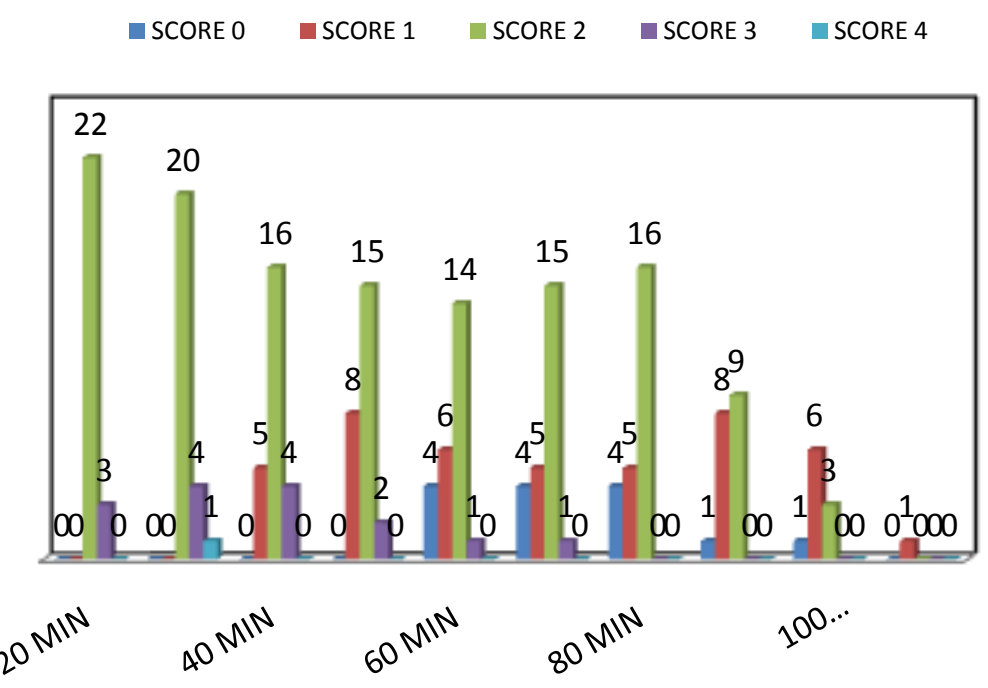

GRAPH-4

SCORES AT VARIOUS TIME INTERVALS TO JUDGE THE DRY OPERAIVE FIELD IN CASE OF GROUP N

SCORE 0 SCORE 1 SCORE 2 SCORE $3 \square$ SCORE 4

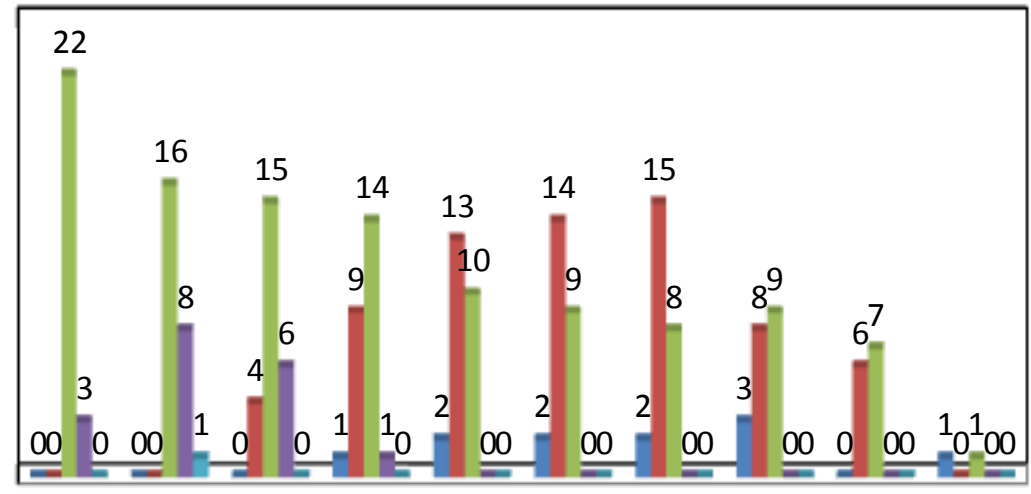

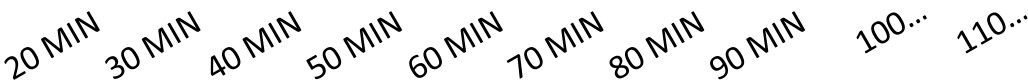


The efficacy of esmolol and nitroglycerine in creating dry operative field by producing.....

\section{Analysis and Discussion}

Spinal surgeries are associated with increased chances of excessive bleeding because of exposed raw surface of the bones during dissection. Controlled hypotension is a safe technique in healthy patients and various studies have proved that controlled hypotension maintains cerebral, coronary renal, spinal cord and splanchnic perfusion ${ }^{[3,4]}$

\section{Choice of drugs for controlled hypotension}

It was in $1985 \mathrm{M}$ Guggiari etal used nitroglycerine for the first time to produce induced hypotensionin aneurismal brain surgery and proved that it can be used a a sole agent for hypotension[5].The decrease in arterial pressure is achieved by vasodilatory effect of NTG on arterial and venous bed resulting finally in decreased venous and right heart filling and so decreased cardiac output.Esmolol is ultra short acting (half life 9 minutes) selective $\beta 1$ antagonist. It has rapid onset and is metabolized by cytosolic esterases in the RBCs.Esmolol offers a favorable balance between myocardial oxygen supply and demand ${ }^{[6]}$.This drug has negative chronotropic effect, hence it effectively increases diastolic time, decreases myocardial metabolism and in turn improves the coronary circulation. A comparative study of sodium nitroprusside and esmolol controlled hypotension for functional endoscopic sinus surgery by Andre Bozaart et al ${ }^{[7]}$ found that esmolol was superior over sodium nitroprusside in providing dry operative field. Another study by Willium S Blau et al ${ }^{[6]}$ comparing esmolol and sodium nitroprusside controlled hypotension for orthognathic surgeries have concluded that esmolol is better than sodium nitroprusside in providing dry operative field.

\section{Haemodynamic variability}

The difference between the mean pulse rates from the $10^{\text {th }}$ minute interval up to recovery in both groups were statistically significant $(\mathrm{p}<0.05)$. (Table 1$)$. This is expected as esmolol is a selective $\beta 1$ adrenergic receptor antagonist thus it has direct action on the $\beta 1$ adrenergic receptors in the myocardium having negative chronotropic effect and leads to bradycardia. No patient in group E suffered from clinically significant bradycardia $<50 / \mathrm{min}$, These findings are comparable with the finding of E Ornstein et al ${ }^{[8]}$ with mean heart rate of $67 \pm 10$ in esmolol group in which they compared isoflurane with esmolol and sodium nitroprusside in patients with Arterio-venous malformations.The mean heart rate in group $\mathrm{N}$ as per table no 1 is consistent with the fact that nitroglycerine causes either no change or slight tachycardia during continuous infusion as slight increase in heart rate is reflex phenomenon, baroreceptor response secondary to hypotension produced. ${ }^{[9]}$

The mean arterial pressure MAP preoperatively in group $\mathrm{E}$ was $88.48 \pm 4.28$ whereas in group $\mathrm{N}$ it was $87.76 \pm 4.62 \mathrm{mmHg}$ which were statistically comparable $(\mathrm{p}>0.05)$. At $5^{\text {th }}$ minute the mean MAP in group E was $69.96 \pm 2.24$ and in group $\mathrm{N}$ was $67.28 \pm 1.33 \mathrm{mmHg}$ which was statistically significant, $(\mathrm{P}<0.05)$. At $10^{\text {th }}, 20^{\text {th }}$, $70^{\text {th }}, 90^{\text {th }}, 100^{\text {th }}$ minute also the differences between the two groups were statistically significant. $(p<0.05)$ (Table2) According to our observations the onset of decrease in heart rate in esmolol group was rapid in onset but the hypotensive response in the esmolol group was slower compared to nitroglycerine group. This may be due to the fact that as esmolol is $\beta 1$ adrenergic receptor antagonist, its effect on heart rate is direct and peak effect should correspond to that time at which the peak plasma concentration is achieved. In a study by Ornstein et al ${ }^{[8]}$ the investigators confirmed that the peak heart rate reduction occurs at 4-7 minutes after the commencement of the infusion. This is consistent with the time taken to attain and maintain a steady state plasma esmolol concentration with the bolus plus infusion dose regimen used.

Reduction in the cardiac output is the pre dominant factor responsible for the hypotensive effect of esmolol, the net total effect of esmolol on blood pressure is determined by the individual effects on cardiac output and systemic vascular resistance. $\beta$ adrenergic receptor antagonists inhibit the release of rennin which mediates systemic vascular resistance.Although it seems reasonable that the effect of esmolol on plasma renin level would be as rapid as the heart rate response, a profound decrease in renin release does not immediately yield a decline in plasma renin level of similar magnitude. The theoretical half life of plasma rennin-angiotensin axis calculated from hepatic clearance is 13 minutes. Thus in our study delay in onset of hypotension in esmolol group compared to heart rate is explainable.

The onset of controlled hypotension is earlier with NTG compared to esmolol (Table 2.) as it has direct vasodilatory action on vascular smooth muscle. Organic nitrates react directly with the nitrate receptors on the vascular smooth muscle cells and produce nitric oxide (NO) which is a potential vasodilator. Also there is activation of intra cellular guanylate cyclase ${ }^{[10]}$ which in turn increases concentration of cyclic adenosine monophosphate which causes vascular smooth muscle relaxation. Recovery from nitroglycerine infusion might be earlier than esmolol as half life of NTG is 1.5 minutes, and that of esmolol is 9 minutes. NTG exhibits high clearance, high volume of distribution, short equilibration time between plasma concentration and haemodynamic effect. Esmolol acts as $\beta 1$ adrenergic receptor antagonist as well as inhibitor of renninangiotensin axis, also it decreases adrenal medullary blood flow, and both the systems take some time to recover after discontinuation of esmolol infusion. 
The efficacy of esmolol and nitroglycerine in creating dry operative field by producing.....

\section{Dry operative field scores}

Several authors have concluded that the quality of the operative field is improved with controlled hypotension, but give little objective evidence to support this conclusion. ${ }^{[1]}$ Willium Blau et al ${ }^{[6]}$ have suggested that it is difficult to measure and compare the blood loss in view of the minute amounts involved and the large volume of irrigating fluid used. Hence the concept of scoring system was introduced to enable the surgeon to make his own assessment of the operating field.Willium Blau et al ${ }^{[12]}$ studied the use of esmolol in creating dry operative field in orthognathic surgeries and found it to be efficacious. Christian Degoute et al ${ }^{[13]}$ found esmolol to be comparable with sodium nitroprusside and remifentanyl in creating dry operative field in tympanoplasty surgery. Nabil Fahmy ${ }^{[14]}$ studied the role of nitroglycerine in producing controlled hypotension in total hip replacement surgeries and found that nitroglycerine was successful in crating effective dry operative field to surgeons' satisfaction. The individual scores at $70^{\text {th }}, 80^{\text {th }}, 90^{\text {th }}$ and $100^{\text {th }}$ minute are of importance as this was the period where the surgeon needed dry operative field the most. In group E, 4 patients had score 0,5 patients had score 1, 15 patients had score 2, and 1 patient had score 3. (Table 3) In group N, 2 patients had score 0, 14 patients had score 1, 9 patients had score 2 and none of the patients had score 3. (Table 3) As per the observations we find that the overall field was better in group $\mathrm{N}$ compared to group $\mathrm{E}$ when we considered the scores at various time intervals individually. At the same time if we look at the mean arterial blood pressures at that intervals then we find that the MAP in group $\mathrm{E}$ is lower than group $\mathrm{N}$ which implies that in group $\mathrm{E}$ the level of hypotension required was lower than group N. (Table 2,3)This also demonstrates that there is no linear co relation between the controlled hypotension produced and the dry operative field achieved which corresponds to findings by Willium Blau et $\mathrm{al}^{[6]}$

NTG causes profound vasodilatation especially venodilatation and results in hypotension. In spine surgery in prone position with $15^{\circ}$ head up tilt the blood pools in the periphery and gravitates away from the operative field. Bleeding is usually pressure dependent, due to veno dilatation the venous pressure further reduces hence bleeding from epidural venous plexus reduces and also the oozing from the raw bone surface.

Esmolol causes decrease in cardiac output by negative chronotropic effect. At the same time due to its adrenergic antagonistic action it decreases systemic vascular resistance. As esmolol is a selective $\beta$ blocker, there is unopposed $\alpha$ receptor stimulation by the catecholamines secreted due to surgical stimulation ${ }^{[7]}$,which causes cutaneous and mucosal blood vessels to contract and prevents bleeding from these mucosal surfaces. Hence esmolol provides dry operative field in those surgeries where mucosal bleeding should be minimized, e.g. open orthognathic surgeries, functional endoscopic sinus surgeries, tympanoplasties. But in case of spinal surgeries blood is lost mostly from the raw bone surface and the epidural venous plexus. In these cases reduced systemic vascular resistance plays a crucial role in reducing bleeding and crating dry operative field. Throughout the investigation in both groups we did not find any ST-T changes or any other abnormal ECG pattern during continuous monitoring. This is consistent with the findings of $\mathrm{N}$ Fahmy et al. ${ }^{[14]}$ In post operative period no untoward events like rebound hypertension, methemoglobinemia, refractory bradycardia were observed. No patient in our study received intra operative blood transfusion

\section{Post operative complications}

In the post operative period 3 patients in group $\mathrm{E}$ and 2 patients in group $\mathrm{N}$ presented with shivering 1 patient in group $\mathrm{E}$ and 2 patients in group $\mathrm{N}$ developed nausea and vomiting post operatively. Our findings correlate with the findings of Caverni V et a ${ }^{[15]}$ and Tikuisis $\mathrm{R}$ et al ${ }^{[16]}$ Symptoms of methemoglobinemia were not observed in any of the patients receiving inj NTG as the duration of infusion was short, maximum up to 2.5 hours and it correlates with findings of Saxon SA et $\mathrm{al}^{[17]}$ and Kaplan KJ et al. ${ }^{[18]}$

\section{CONCLUSION}

Both Esmolol and NTG can be used as a sole agent to create dry operative field in spine surgeries by way of controlled hypotension with comparable efficacy.However NTG is more economical than Esmolol for this purpose.Also dry operative field with NTG can be achieved at higher mean blood pressure values compared with use of esmolol hence it appears that there is no linear correlation between the dry operative field achieved and the induced hypotension produced.

\section{BIBLIOGRAPHY}

[1]. Wylie, C.D.s., A Practice Of Anaesthesia, in A Practice Of Anaesthesia, P.R.K. Thomas E J Healy, Editor. 2003, Arnold

[2]. Nilesh J Patel, B.S.P., et al, Induced moderate hypotensive anaesthesia for spinal fusion and Harrington rod instrumentation. The Journal of Bone and Joint Surgery, 1985. 67A(9): p. 1384-1387.

[3]. 3. Gale E Thomson, R.D.M., et al, Hypotensive Anaesthesia for Total Hip Arthroplasty. Anaesthesiology, 1978. 48(2): p. $91-96$.

[4]. D Andel, H.A., et al, The influence of deliberate hypotension on splanchnic perfusion balance with use of either isoflurane or esmolol and nitroglycerine. Anesthesia and Analgesia, 2001. 93: p. 1116-1120.

[5]. Guggiari, M., et al., Use of nitroglycerine to produce controlled decreases in mean arterial pressure to less than $50 \mathrm{~mm} H \mathrm{H}$ Br J Anaesth., 1985. 57(2): p. 142-7. 
The efficacy of esmolol and nitroglycerine in creating dry operative field by producing.....

[6]. Willium S Blau, E.R.K., et al, Esmolol is more effective than sodium nitroprusside in reducing blood loss during orthognathic surgery. Anesthesia and Analgesia, 1992. 75: p. 172-178.

[7]. Andre' P Boezaart, e.a., comparison of sodium nitroprusside and esmololinduced controlled hypotension for functional endoscopic sinus surgery. Canadian Journal of Anesthesia, 1995. 42(5): p. 373-376.

[8]. E Ornstein, W.L.Y., et al, Deliberate hypotension in patients with intra cranial arteriovenous malformations: esmolol compared with isoflurane and sodium nitroprusside. Anesthesia and Analgesia, 1991. 72: p. 639-644.

[9]. Jan Hauss, K.S., et al, Nitroprusside and nitroglycerine induced hypotension: effects on haemodynamics and on the microcirculation World Journal of Surgery, 1982. 6: p. 241-250.

[10]. Abrams, J., Pharmacology of nitroglycerine and long acting nitrates. American Journal of Cardiology, July 1985. 56: p. 12A-16A.

[11]. Glenn A Fromme, R.A.M., et al, Controlled Hypotension for Orthognathic surgery. Anesthesia and Analgesia, 1986. 65: p. 683-686.

[12]. Willium S Blau, E.R.K., et al, Esmolol is more effective than sodium nitroprusside in reducing blood loss during Orthognathic surgery. Anaesthesia and analgesia, 1992. 75: p. 172-178.

[13]. Christian S Degoute, M.J.R., et al, Remifentanyl and controlled hypotension; comparison with nitroprusside or esmolol during tympanoplasty. Canadian Journal of Anesthesia, 2001. 48(1): p. 20-27.

[14]. Fahmy, N.R., Nitroglycerine as a hypotensive drug during general anaesthesia Anaesthesiology, July 1978. 49(1): p. 1720.

[15]. Caverni $\mathrm{V}$ et al, Hypotensive anesthesia and recovery of cognitive function in long-term craniofacial surgery. Journal of Craniofacial Surgery, 2005 16(4): p. 531-536.

[16]. Tikuisis R et al, Controlled hypotension in transthoracic esophageal resection. Medicina (Kaunas). 2004. 40: p. Suppl $1: 174-8$.

[17]. Saxon SA et al, Effects of continuous infusion of intravenous nitroglycerin on methemoglobin levels. American Journal of Cardiology, 1985. 56(7): p. 461-464.

[18]. Kaplan KJ et al, Association of methemoglobinemia and intravenous nitroglycerin administration. American journal of cardiology, 1985. 55(1): p. 181-183. 